\title{
CHAPTER 21
}

\section{THE IMPORTANCE OF EFFECTIVE WORKING RELATIONSHIPS BETWEEN SALES AND MARKETING}

Kenneth Le Meunier-FitzHugh and Graham R. Massey

1st June 2009

\subsection{INTRODUCTION}

Modern organizations are typically composed of functionally specialised departments such as Finance, Manufacturing, R\&D, Sales, and Marketing. These departments are to a large extent interdependent when coordinating their activities to service external customers. One of the key roles of these departmental managers is therefore to forge effective ongoing “cross-functional relationships” (CFRs) with other managers. One of the most important of these is the Sales Manager/Marketing Manager CFR, as they are both customer-facing and share a number of broadly similar objectives, e.g., to identify and secure new customers, to build market share, and to service and build revenues with existing customers to ensure the long-term profitability of the company. However, despite the importance of Sales/Marketing CFRs, until relatively recently, they have not attracted much attention in the academic literature. Now, a strong body of scholarly work on this CFR is starting to emerge, and the topic is creating 
considerable academic interest (e.g., Dawes and Massey, 2005; Homburg and Jensen, 2007; Kotler, Rackham and Krishnaswany, 2006; Le Meunier-FitzHugh and Piercy, 2007a; Massey and Dawes, 2007). The rationale for this growing interest is clear: that improving Sales/Marketing CFRs can add value to customers, and ultimately, improve an organization’s market performance (Guenzi and Troilo, 2007; Le Meunier-FitzHugh and Piercy, 2007b).

From a customer's standpoint the sales and marketing departments could be viewed as a single function, and be expected to work effectively together to deliver value to customers. However, Sales and Marketing often operate as separate departments with different cultures, objectives, and values. Over time, the Sales and Marketing departments have developed very different philosophies and strategies to fulfil their roles within the organization, and these differences maybe a critical factor in their individual success as a department, and can even impact on the overall success of the organization (Homburg and Jensen, 2007).

Given the separation of the Sales and Marketing functions into different departments, it is in the interests of organizations to understand Sales/Marketing CFRs, to improve organizational performance. However, many organizations are unsure how to best manage these CFRs. The objective of this chapter is to review the current thinking on Sales/Marketing CFRs, and consider a range of controllable and uncontrollable factors that may influence the effectiveness of this interface. We begin by detailing the contextual conditions under which Sales and Marketing relationships are enacted, e.g., the interdependence between the functions, the key measures of the effectiveness of Sales and Marketing relationships, and the level of conflict in this CFR. In addition, we will also discuss the main factors that are believed to influence Sales and Marketing CFRs, including organizational structure and management 
attitudes towards coordination. We will then review some of the tools and techniques that may be used to influence the interface e.g., lateral linkage devises, and managerial use of influence tactics. The chapter will conclude with consideration of the key relationship variables that have the greatest effect on performance; the types of communication prevalent in CFRs, and interpersonal trust between Sales Managers and Marketing Managers.

\subsubsection{Vignette: Introduction}

Because many modern organizations split Sales and Marketing into separate, but interdependent departments, one of the key roles of managers is to develop effective cross-functional relationships (CFRs). Why is this necessary? In part it relates back to Porter's (1985) “value chain,” and in particular, the internal coordination required to serve effectively and satisfy external customers.

Consider the day to day functioning of a typical organization which manufactures goods for sale into either business-to-business or business-to-consumer markets in the following vignette:

\section{$\underline{\text { The Sales Manager's Tale - A New Major Customer Places an Order }}$}

After much time and effort, the Sales Manager of a manufacturing company has secured an order from an important new customer, one likely to purchase a significant amount of product in the future. To satisfy this new customer however, the Sales Manager depends on virtually every other department in the organization. Let's see why.

The product to be supplied will only require minor modifications to an existing product. But is it likely that $R \& D$ will drop what they are currently working on to make these changes? No, it is not. They may even have strong reservations about doing this as it would require them to test the new product, ensure that could be manufactured efficiently, and at an acceptable standard cost. Moreover, this will need to be done to a strict timetable, as the customer requires these products by a fixed date.

The Sales Manager therefore needs to work closely with the R\&D Manager, to convince them of the importance of the new account, and to increase the priority of this customer's product, to the detriment of other current projects. However, the R\&D Manager is a good friend of the Sales Manager and they have worked together for a long time. They both trust each other's competence, and like each other. The R\&D Manager understands the importance of this customer to the organization and has 
agreed to prioritise this project. Can the Sales Manager feel confident that the order will be filled by the due date? Sadly not, as there are other managers who need to be approached to deliver this order on time.

Are there for example, sufficient raw materials on hand to manufacture these new products? If not, the Sales Manager will need the Purchasing Manager to raise some purchase requisitions. If new packaging is required, this will also need to be sourced and then a commercial quantity of the packaging ordered. There are a few things in the Sales Manager's favour in getting the Purchasing Manager to do these things. First, the Sales Manager is very well regarded by the General Manager, because of an excellent track record of securing large customers, and the Purchasing Manager is aware of this. Also, the Purchasing Manager is new to the organization, and has noticed that the General Manager places great importance on departments within the organization working more closely with each other. Clear signs of this are the frequent cross-functional job rotations, and the use of joint incentives and rewards for separate departments that are working on joint projects.

The next priority is to liaise with the Marketing Manager to ensure that the designs for the new packaging with meet the customer's requirements. Further, the customer has requested some point of sale materials and leaflets to promote the new products. As there is an opportunity to develop further promotions with this client in the future, the Marketing Manager happy to provide this expertise within the time frame available.

The Sales Manager now is confident the promotional and raw materials are in hand, and that R\&D can modify the product to the required technical specifications. However, the Sales Manager isn't able to breathe easy yet. They need to liaise with the Production Manager to schedule this order into their production runs. This manager is very busy, and has two production shifts running per day, with all machines fully deployed. There is already a backlog of products to manufacture for existing orders and for stock, and the Production Manager isn't exactly excited about this new order, as it will affect the smooth operation of the factory. Machines will need to be redeployed, and extra staff will be required, perhaps at overtime rates. All of this will disrupt the Production Manager's normal work.

However, the Sales Manager has managed to convince the Production Manager to schedule this new order into a production run. One reason for this was that the Sales Manager pointed out to the Production Manager that if this new client is secured on a long-term basis, it will lead to large, ongoing orders. This will help the Production Manager justify their capital expenditure request for two new machines. Can the Sales Manager now get a good night's sleep? No, not yet at least! There are other things to consider.

The company has a policy for all new accounts; a strict 30-day requirement applies for accounts receivable. However, the new customer is a large, highly reputable organization that is likely to place large orders for at least the next 12 months. Also, they are unlikely to default on their account. They have requested 90days, though the Sales Manager knows that this is against company policy. The Sales Manager now needs to talk to the Finance Manager! The Finance Manager recognises the opportunity that this new client represents for the organization as a whole, and agrees to waive the usual rules relating to the new customer.

The Sales Manager has to do far more than simply prospecting, qualifying, targeting, convincing, and finally securing an order from a high potential customer. When the order comes in, it will automatically be filled without any further action by the Sales Manager. The Sales Manager will need to take considerable time, and apply 
some fairly sophisticated techniques of argument, and persuasion, and exercise various forms of power and influence to get the order filled, and to meet their own personal and departmental objectives. This is why cross-functional relationships are vital within organizations, and why Sales Managers require a good understanding of them, to allow them to better achieve their own personal and professional goals.

\subsection{THE ORIGINS AND IMPORTANCE OF CROSS-FUNCTIONAL RELATIONSHIPS}

\subsubsection{Functional Interdependence}

As the Sales Manager's Tale above illustrates, managers and departments within organizations are often highly interdependent. This can be in a linear fashion, i.e., where one manager provides inputs to a downstream manager, e.g., the Production Manager depends on the Purchasing Manager to ensure that adequate, timely stocks of raw materials are available for production runs. Interdependence can also be reciprocal where one manager provides inputs for the other manager and vice versa. Sales Managers and Marketing Managers for example have this form of interdependence. Sales rely on Marketing for marketing research reports, customer satisfaction survey results, and for advertising and sales support materials to be used in the field by the salesforce. Conversely, Marketing relies on Sales for information from key customers, ideas for new products, and for information on competitive activity. Sales and Marketing Managers therefore need to recognise their interdependence, and forge effective CFRs with those interdependent managers.

One way to think about cross-functional interdependence is in terms of “internal marketing” (e.g., Ballantyne, 1997; Grönroos, 1981). Gummesson (1991) has suggested for example that interactions between departments and their managers can be thought of as supplier-customer relationships within an internal market. Indeed George (1990) argues that effective internal exchanges between managers and their departments, is a prerequisite for successful exchanges with external markets, i.e., the organization's customers. 
One can also conceptualise CFRs as part of an organization's “market orientation” (see Kohli and Jaworski, 1990; Narver and Slater, 1990), i.e., an organization's disposition to continuously deliver superior value to their customers. Narver and Slater (1990) argue that market orientation requires a customer orientation, a competitor orientation, and importantly inter-functional coordination. As we will see later in this chapter, this internal cross-functional coordination is strongly influenced by the effectiveness (or otherwise) of an organization's CFRs.

\subsubsection{Cross Functional Relationships}

CFRs are important for any organization which has separate, specialised departments under the control of different managers. There is a large body of evidence on the importance of these CFRs. Effective CFRs have performance implications not only for individual departments and their managers, but for interdependent managers and their departments, and also for the organization as a whole. Better cross-functional coordination is known to significantly improve service delivery to external customers (e.g., George, 1990; Lovelock, 2000). Also, effective Marketing/R\&D CFRs are vital for organizations seeking to develop successful new products (e.g., Massey and Kyriazis, 2007; Souder, 1981; 1988). This is important as many organizations recognise that much of their future income, and indeed their survival, hinges on their ability to continue to develop new products. Similarly, effective Marketing/Information Technology CFRs are vital to good customer relationship management (e.g., Winer, 2001).

As mentioned previously, until recently Sales/Marketing CFRs have not attracted much attention in the academic literature. This is surprising, as it is now widely recognised that the Sales/Marketing CFR is one of the most important relationships within organizations, particularly those with a strong focus on customer 
satisfaction. Sales/Marketing CFRs are vital to the efficient operation of an organization, because Sales implement Marketing's strategies at an operational, dayto-day level (Strahle, Spiro and Acito, 1996). In this following section we review the key outcomes of Sales/Marketing CFRs, and demonstrate their importance within organizations.

\subsection{PERFORMANCE OUTCOMES}

The relevant performance outcomes of Sales/Marketing CFRs can be broadly classified into "task" outcomes, and "psychosocial” outcomes. We define and review these two types of outcome, and also reveal the links between them. Sales Managers and Marketing Managers have a shared responsibility within organizations to work together effectively to achieve the task/performance outcomes that will satisfy the organization's stakeholders.

\subsubsection{Metrics}

The key measures or metrics of an organization's sales performance come in various forms. First, there are the "hard" measures, such as the overall quantity of goods sold, and there may be targets set for these by “stock-keeping unit” (SKU), by product/brand, and by category. The performance of the Sales Department, the Marketing Department, their managers, and the organization's salespeople will be judged against these targets and this is a relatively straightforward thing to do.

A similar "hard" measure might be market share. Again, it is likely that organizations will have set targets for market share, by SKU, by product/brand, and by category, and again, performance will be judged against these targets. "Softer" measures also exist, such as measures of “customer satisfaction,” and an important aspect of the new service-dominant logic to marketing (see Vargo and Lusch, 2004) is that customers and their satisfaction are at the core of value creation. Accordingly, 
many organizations routinely track customer satisfaction, and use this as a key metric of their market performance.

What is the link between Sales/Marketing CFRs and these outcome variables? If you had already begun to suspect that the link is not as direct as we might like, you are correct. Many things can contribute to achieving sales targets, market share and customer satisfaction, including the organization’s advertising and sales promotions, and whether they are trade or consumer targeted. They may also have experienced production or quality control problems, inability to source raw materials, or simply run out of stock. External events can also affect performance, e.g., competitors’ advertising and sales promotions, or new products launches.

So what exactly is the role of Sales/Marketing CFRs in this? How do we assess the contribution of these CFRs to these performance outcomes? Until recently most of the evidence of the importance of effective CFRs to these hard performance outcomes was indirect. Good evidence exists for example, from other CFRs that the more effective they are, the better the task outcomes from joint project work. Some of the most compelling evidence on this comes from studies of the effectiveness of Marketing/R\&D CFRs during new product development (NPD) projects. Souder (1988) studied both industrial and consumer goods organizations and found strong evidence that when Marketing/R\&D CFRs were "harmonious”, most of the NPD projects were either partially, or fully successful. In contrast, where there was severe disharmony in the CFR, most of these projects were considered to be failures. More recently however, empirical evidence has for the first time established a link between the "effectiveness of Sales/Marketing relations," and "superior value creation,” and “market performance” (Guenzi and Troilo, 2007). Similarly, Le Meunier-FitzHugh and Piercy (2007b) and Homburg and Jensen (2007) found strong 
links between improved collaboration between Sales and Marketing, and superior business performance. Hence whilst the importance of effective Sales/Marketing CFRs are intuitively obvious, we now finally have some relatively "hard” evidence that they are an important determinant of organizational performance.

\subsubsection{Psychosocial Outcomes}

Now that a direct link between the effectiveness of Sales/Marketing CFRs and "hard" performance measures has been established, we should review the evidence regarding the "soft" measures of Sales/Marketing effectiveness, as we can be fairly confident that this will lead to performance on the "hard" measures. "Psychosocial” measures are those which have psychological or social components e.g., the extent to which managers perceive their CFRs to be effective, and the levels of dysfunctional conflict in these CFRs (see Ruekert and Walker, 1987).

One interesting aspect of the literature on these psychosocial outcomes is the view that Sales/Marketing CFRs are usually ineffective, and fraught with conflict. Early qualitative work (e.g., Cespedes, 1993) and anecdotal accounts (e.g., Carpenter, 1992) for example suggests that this CFR is problematic, and Dewsnap and Jobber's (2000) summary of the literature notes that it is characterised by negative outcomes a lack of cohesion, distrust, and dissatisfaction. Recent small sample empirical work (e.g., Kotler, Rackham and Krishnaswany, 2006), and exploratory work (e.g., Biemans and Brenčič, 2007; Guenzi and Troilo, 2006) supports this view. There is however no definitive evidence about whether Sales/Marketing CFRs problems are endemic, and some studies suggest that Marketing/Sales CFRs may be more effective and harmonious than is generally believed (e.g., Dawes and Massey, 2005; Massey and Dawes, 2007a,b). 


\subsubsection{The Perceived Effectiveness of Sales/Marketing Relationships}

One variable that has been used to assess the quality of Sales/Marketing CFRs is “perceived relationship effectiveness” (PRE) (e.g., Massey and Dawes, 2006; 2007). This variable relates to how worthwhile, equitable, productive, and satisfying a manager perceives their working relationship to be with the other manager. This is a useful psychosocial outcome variable for various reasons. First, a number of important existing studies of working relationships have also focused on subjective outcomes (e.g., Anderson and Narus, 1990; Smith and Barclay, 1999). Secondly, objective, "hard” measures of effectiveness (e.g., sales volume) may not accurately reflect the quality of a relationship due to confounding factors such as long sales cycles (Smith and Barclay, 1997). Last, as noted above, positive perceptions about the effectiveness of one’s CFRs are known to be associated with improvements in hard outcomes.

Little hard data exists on PRE in Sales/Marketing CFRs, though the results of these few studies are generally quite encouraging (Dawes and Massey, 2006; Massey and Dawes, 2007a,b). Their results reveal that on average PRE is quite high, however within their samples there were a significant number of ineffective Sales/Marketing CFRs. So, whilst there is not universal harmony in this CFR, and there are definitely organizations in which Sales and Marketing are at war, a good proportion of organizations seem to enjoy quite high levels of PRE in Sales/Marketing CFRs. In summary, the jury is still out on whether these relationships are as ineffective as is commonly assumed. However, there is evidence to show that improvements in this CFR are beneficial. We will return to this point below when we reveal the evidence on the psychosocial variable “conflict” between Sales Managers and Marketing Managers. 


\subsubsection{Conflict in Sales/Marketing Relationships}

There is some debate as to whether conflict between Sales and Marketing functions is detrimental or beneficial to efficiency and business performance. Some deeper insights can be found in the notion that there are at least two distinct types of conflict in CFRs - dysfunctional conflict which result in negative outcomes and poor performance, and functional conflict that results in more positive outcomes in terms of efficiency driven by healthy competition and an open exchange of ideas and views (e.g., Menon, Bharadwaj and Howell, 1996; Song, Xie and Dyer, 2000). As Barclay (1991:145) noted "Conflict can have constructive or destructive outcomes depending on its management, and an emphasis on managing conflict requires a discriminating understanding of its causes”. However, the distinction between functional and dysfunctional conflict may be considered simplistic if viewed as two ends of a continuum. The two concepts should be treated as separate variables that incorporate the full range of consequences outlined in the organizational behaviour literature from which they originated (e.g., Jehn and Mannix, 2001). Below we review the theory and evidence for the prevalence of these two forms of conflict in Sales/Marketing CFRs.

\subsubsection{Dysfunctional conflict}

Dysfunctional conflict is known to be a powerful variable within relationships such as CFRs, and is associated with a range of negative outcomes including the distortion and withholding of information to the detriment of others within the organization, hostility, and distrust during interactions (Thomas, 1990; Zillman, 1988), opportunistic behaviour (Barclay 1991), information gatekeeping (Jaworski and Kohli, 1993), and the creation of obstacles to decision making (Ruekert and Walker, 1987b). Dysfunctional conflict is also believed to reduce team performance and member satisfaction, because the associated tension and antagonism can distract 
people from their task performance (De Dreu and Weingart, 2003). Dysfunctional conflict is generally unhealthy, and associated with dysfunctional behaviours, dissatisfaction, and poor individual and/or group performance. It is therefore an important outcome variable to investigate when diagnosing Sales/Marketing CFRs

There are many reasons cited for the lack of co-operation between Sales and Marketing, including that they have developed strong group identities, very different philosophies and that staff often have different educational backgrounds (Griffin and Hauser, 1996; Lorge, 1999; Dewsnap and Jobber, 2000). This has led to the development of two very different cultures and working practices between the two groups (Beverland, Steel and Dapiran, 2006). Homburg and Jensen (2007) suggest that sales and marketing exhibit two different 'thought worlds' based on alternative orientations and competences, but that these different perspectives are necessary to perform their individual functions effectively. Major problems arise when Sales and Marketing departments become independent "silos” with poor cross-functional communications (Dewsnap and Jobber, 2000; Olsen, Cravens and Slater, 2001; Rouzies et al, 2005; Le Meunier-FitzHugh and Piercy, 2007a). Sales and Marketing functions may also find themselves in competition for resources and/or have differing perspectives on how to achieve their objectives, which may lead to dysfunctional conflict (Anderson, Dubinsky and Metha, 1999; Olsen, Cravens and Slater, 2001; Kotler, Rackham and Krishnaswamy, 2006).

A number of dysfunctional activities have been observed in the Sales/Marketing CFRs, e.g., working at cross-purposes, being obstructive and not appreciating each other's roles in achieving marketing objectives. It may be too easy for example, for the marketing department to ignore immediate concerns in the market place and focus on long term objectives e.g., creating brand value, or 
launching new products; and for the sales department to become focussed on achieving short-term sales objectives (Cespedes, 1995; Lorge, 1999). In addition, Sales repeatedly complain that support tools provided by marketing are inadequate, and marketing frequently accuses sales of misunderstanding or misusing marketing collateral. As a result, some scholars suggest that reducing dysfunctional conflict created by interdepartmental competition for scarce resources should be an objective of senior managers (e.g., Kotler, Rackham and Krishnaswamy, 2006).

Dysfunctional conflict between sales and marketing may result in customers observing inconsistencies in their interactions with the organization, resulting in damage to their relationship with the organization. This can lead to a reduction of performance. Further, Song, Xie and Dyer (2000) found that the increasing crossfunctional conflict led to a greater chance that the departmental managers concerned would withdraw from the relationship rather than collaborate. Dysfunctional conflict can therefore lead to distrust that is detrimental to both cross-functional collaboration and efficient performance (Colletti and Chonko, 1997; Dewsnap and Jobber, 2002; Dawes and Massey, 2005; Biemans and Brencic, 2007).

Although there is some evidence to indicate that dysfunctional conflict exists in Sales/Marketing CFRs, but it may not necessarily be endemic or inevitable. Two quantitative studies, Dawes and Massey (2005) and Le Meunier-FitzHugh and Piercy (2007b) for example found that dysfunctional conflict was low between sales and marketing functions. So things may not be as bad as is often believed, which is good news for both Sales Managers and Marketing Managers as they do not inevitably have to be in conflict. As there are only a few large scale studies examining dysfunctional conflict in Sales/Marketing CFRs, more research is required to answer this question. However, as things currently stand there is a positive message in these results, i.e., do 
not immediately assume that there has to be dysfunctional conflict in this CFR, treat each situation as it comes. Also, if there is dysfunctional conflict in this the Sales/Marketing CFR, take proactive steps to resolve this.

\subsubsection{Functional conflict}

Much of the existing literature on relationships such as CFRs has taken a rather simplistic view of conflict, i.e., that it is always bad, and management need to reduce it wherever possible. It is now increasingly recognised however, that conflict can also have a functional form ("functional conflict"), in other words, it can be beneficial to CFRs, and to the organization as a whole (See Amason, 1996 for a good review of functional conflict). Functional conflict is important as it involves consultative interactions, and useful give and take. Where functional conflict is present, people feel free to express their opinions, and to challenge others' ideas, beliefs and assumptions, and people respect others' viewpoints even when they disagree. (e.g., Baron, 1991; Cosier, 1978; Schwenk, 1989; Tjosvold, 1985). Functional conflict can be considered an antidote to "groupthink" (De Dreu, 1997) where feelings of solidarity and loyalty to a decision-making group override the imperative to logically and realistically evaluate all options (Filley, 1970).

Few studies exist in the marketing literature examining functional conflict.

The first major study was by Menon, Bharadwaj, and Howell (1996), which examined functional and dysfunctional conflict in Marketing CFRs, and reported quite high levels of functional conflict. Similarly, Massey and Dawes (2007a) found high levels of functional conflict in Sales/Marketing CFR, and again these results give Sales Managers and Marketing Managers some basis to believe that they are not inevitably going to be involved in dysfunctional and ineffective relationships with each other. This is important because where functional conflict is present "individual departments 
exhibit not only a willingness to consider new ideas and changes suggested by other departments but also to volunteer information and ideas to others within the organization” (Menon, Bharadwaj and Howell, 1996:303). It may be that functional conflict may help to reduce "silo" mentalities, and feelings of group loyalty that may prevent the consideration of other possible options and "even if there are disagreements, discussions focus on issues rather than on people” (Massey and Dawes, 2007:1122). Challenging others ideas and beliefs may result in positive exchanges and have been linked to innovation and sales success as parties consider alternatives and challenge their assumptions, thereby improving the quality of their decision-making (Menon, Bharadwaj and Howell, 1996).

There are compelling arguments for maintaining some tension between Sales and Marketing. Sales activities require different skills and personal attributes than marketing activities and the different perspectives of the two groups may be necessary to maintain efficient/optimum performance (Shapiro, 2006; Homburg and Jensen, 2007). Sales and Marketing staff will need to maintain the ability to freely discuss solutions and consider each others' perspective and information. This will help to establish open communication and greater collaboration.

\subsection{FACTORS INFLUENCING THE EFFECTIVENESS OF SALES AND MARKETING CFRs}

Various factors can influence the effectiveness of CFRs, and these fall into two broad categories. There are the formal, structural/bureaucratic influences such as "formalisation" and "centralisation” and the physical structure and location issues that may facilitate or obstruct CFRs. Further, there is the key factor of senior managers’ attitudes towards coordination. We will now review these influences.

\subsubsection{Structural/Bureaucratic Factors}


The internal workings of functionally specialised organizations are complex. With the division of labour, functional specialists tend to be located within their own separate departments, bringing with it the need to coordinate the activities of those departments (see the opening vignette of this chapter, The Sales Manager's Tale). The most frequently employed method for this involves "organizational structure" or “bureaucracy”, as senior management need to actively encourage cross-functional integration by implementing appropriate structures (Ayers, Dahlstrom and Skinner, 1997). (See the seminal work of Max Weber - Weber 1924, translated by Talcott Parsons in 1947). The key features of Weber's bureaucracy for CFRs are “centralisation” (of decision-making), and “formalisation” (of policies, rules, and procedures when performing one’s job). Formalisation helps coordinate an organization's activities by reducing variability in behaviour, in order to predict and control those behaviours (Mintzberg, 1979). Formalisation reduces confusion because staff know what they are expected to do, and it therefore helps coordinate effort (Thompson, 1967).

Centralisation is the extent to which decisions are made at higher levels in an organization's hierarchy (Aiken and Hage, 1968). A key issue facing top management is to trade-off control against greater adaptability from decentralisation (McCann and Galbraith, 1981). Routine tasks such as normal production runs require only "mechanistic" structures, i.e., high formalisation and centralisation. However, in situations of high task uncertainty, or where creativity and innovation are required (e.g., NPD projects), more “organic”, less formalised and centralised structures are appropriate (Burns and Stalker, 1961; Olsen, Cravens and Slater, 1995). Whilst there is no hard evidence on the effects of Weber's (1924) structural/ bureaucratic variables in Sales/Marketing CFRs, evidence from other Marketing 
CFRs can provide insights. Massey and Kyriazis’s (2007) study of Marketing/R\&D

CFRs during new product development, for example found that formalisation enhanced cross-functional integration because it was positively associated with increased communication between these managers. Given that cross-functional integration is increased through effective communication, formalisation may be useful to help integrate Sales and Marketing. The opposite was found for centralisation, i.e., higher centralisation appears to suppress cross-functional communication, and would therefore act as a barrier to Sales/Marketing integration.

\subsubsection{Location and Physical Structure of Sales and Marketing}

It has been suggested that the location and physical structure of sales and marketing may affect their ability to work collaboratively, meet organizational goals more effectively and reduce conflict (e.g., Germain, Droge and Daugherty, 1994). Le Meunier-FitzHugh and Piercy (2008) found that sales and marketing may be found in a number of different locations; within a single office, in two separate offices in one building, or in separate buildings/continents. There does not seem to be a standard way of physically structuring sales and marketing functions.

It has been proposed that closer physical proximity of the sales and marketing functions may lead to an increased perception of achieved integration and lower conflict of interests (Dewsnap and Jobber, 2000). Further, creating structural links between sales and marketing, for example by placing a senior manager in charge of both sales and marketing functions, may help to improve communications and help to align activities (Rouzies et al., 2005; Matthyssens and Johnston, 2006; Oliva, 2006). However, recently Dawes and Massey (2005) found that changing the physical structure did not have an effect on Sales/Marketing CFRs and had little impact on collaboration between sales and marketing. Further, no correlation was found between 
a particular structure for sales and marketing and superior performance (Le MeunierFitzHugh and Piercy, 2008). Changing location or physical structure to alter working practices or implement organizational changes may create new challenges and problems for the organization to overcome (Bartlett and Ghoshal, 2000; Hammer, 2001; Homburg, Workman and, Jensen 2000) and is therefore unlikely to be effective on its own.

Sales and marketing perform very different functions that may benefit from a particular configuration, and research suggests that there is little difference in interfunctional conflict or collaboration in organizations operating as two separate sales and marketing departments or as a single joint department (Le Meunier-FitzHugh and Piercy, 2008). The existing physical structure and location of sales and marketing departments is likely to be based on historical and cultural factors as well as industry norms, and will probably be effective for that organization and industry. However, there are many reasons why these two groups should develop the mechanisms and processes to improve their ability to collaborate to the benefit of the organization and its business performance (Shapiro, 2002; Le Meunier-FitzHugh and Piercy, 2007b). The location and physical structure of sales and marketing does not appear to have a significant of impact on the effective operation of their functions.

\subsubsection{Senior Management Attitudes}

Studies of Marketing/R\&D CFRs stress the value of working together to achieve common goals to the benefit of both departments (e.g., Lucas and Busch, 1988; Krohmer, Homburg and Workman, 2002) and the creation of common goals is one function of senior management (Viswanathan and Olson, 2003). The Sales Manager's Tale also illustrates this idea through the General Manager's use of job rotation and joint incentives and rewards, which demonstrate explicit top management support for 
cross-functional integration. Senior managers who have bought into the concept of creating internal collaboration will be able to share a vision of how the culture of the organization operates. They are also in a position to create processes that help to build and establish a shared vision that can lead to staff achieving more than they thought they could (Senge, 1990). Managers should be seen to take responsibility for the complex relationship between Sales and Marketing as the staff may not prioritize collaboration if they do not (Holden, 1999). Management involvement in creating positive CFRs will encourage staff to 'buy in’ to working from a more collaborative basis (Athens, 2002).

One of the key factors in Sales/Marketing CFRs is that Sales' targets are often short term, while Marketing's targets may be focussed on the longer term (Webster, 1997). However, senior managers may have difficulty in balancing the costs and benefits of short-term and long-term financial performance (Gupta, Raj and Wilemon, 1985; Webster, 1997). Sales and Marketing are frequently set different goals by senior management that may mean that they are working at cross-purposes (Lorge, 1999; Piercy, 2006; Rouzies et al., 2005; Strahle, Spiro and Acito, 1996). It has been suggested that joint planning may provide a basis for aligned objectives. If targets are set jointly then the overall all direction and individual contributions to achieving objectives may become explicit (Le Meunier-FitzHugh and Piercy, 2007a, b). Managers may be able to clarify overlapping activities and those that are mutually dependent, especially where there is potential for role ambiguity (Menon, Bharadwaj and Howell, 1996). Senior management should be focussed on aligning values and objectives, facilitating a better understanding of Sales and Marketing roles, and fostering CFRs (Schmonsees, 2006). 
If senior managers are not focussed on, or do not understand, the issues involved in creating improved CFRs, then there is little chance that they can be addressed effectively. To achieve greater collaboration between Sales and Marketing, senior managers have to acknowledge the need to improve the interface, understand the existing relationships and be able to create clear strategies to facilitate improvement; for example by sharing objectives, supporting joint planning, aligning activities and communicating the importance of collaboration (Le Meunier-FitzHugh and Piercy, 2009). Sales and Marketing groups should be given clear and specific direction on what has to be achieved, and an understanding of how the other's role contributes to achieving the organization's objectives.

There are a number of coordination mechanisms that are available to managers who wish to improve the Sales and Marketing CFR and these will be reviewed in the next section.

\subsection{COORDINATION MECHANISMS}

There are two types of coordination mechanism that may be employed to improve Sales and Marketing CFRs, lateral linkage devices such as cross-functional job rotation, joint incentives and rewards, and managerial use of influence tactics. In this section we consider how effective these coordination mechanisms may be in Sales/ Marketing CFRs.

\subsubsection{Lateral Linkage Devices}

As already established, organizations structured along functional lines into separate departments require effective CFRs to become a cohesive whole, where each unit contributes to organizational goals and satisfies external customers. To improve collaboration, management often employ “lateral linkage devices” (see Olson, Walker, and Ruekert, 1995). A wide variety of these devices are advocated in the 
literature. For example, joint incentives and rewards (Saghafi, Gupta, and Sheth, 1990; Souder and Chakrabati, 1978), the use of “integrators,” i.e., persons specifically responsible for facilitating cross-functional cooperation (Lawrence and Lorsch, 1967b; Souder, 1977), cross-functional teams (Lawrence and Lorsch 1967a), job rotation and personnel movement across functional boundaries (Griffin and Hauser, 1996), periodic clarification of roles, and relocation of personnel to improve interpersonal communication flows (Allen and Fustfeld, 1975). In the Sales Manager's Tale, the General Manager uses two of these lateral linkage devices (job rotation, and joint incentives and rewards) to help integrate departments within the organization.

Whilst some of these devices were found to be effective in other contexts, e.g., Marketing/R\&D CFRs, there is little evidence as to their effects in Sales/Marketing CFRs. Theory suggests that it may be due to characteristics of the organization, e.g., goods versus services organizations, consumer versus business-to-business organizations. Massey and Dawes (2001) however found no differences between business-to-consumer organizations, and business-to-business organizations in the perceived effectiveness of any linkage device. However, their results did suggest that for organizations selling into both types of market, joint incentives and rewards; using cross-functional teams; using "facilitators;" and exchanging documents, were more effective than in organizations which sold only into one of these types of market. These results are therefore consistent with organizational theory, i.e, that complex organizations require greater efforts to cross-functionally re-integrate. Similarly, goods producers used more integration methods than service providers, and this makes sense given that goods producers are typically more complex than service 
providers. It may therefore be important for goods-producers to bear this in mind, and consider using a range of lateral linkage devices, rather than just one.

Beyond these findings for complex organizations, there is still the issue of why the effectiveness of these devices is the same in less complex organizations. One possible explanation is that it may not matter what method is used, but what is important is that senior management are seen to be taking an active interest in attempting to integrate the two departments (e.g., Cass and Zimmer, 1975). By doing this, senior management are demonstrating the importance they attach to improving cross-functional integration, and in these circumstances even "weaker" linkage devices may be more effective than might otherwise be expected. In the Sales Manager's Tale the Purchasing Manager is clearly aware of the importance the General Manager places on cross-functional integration, and thus quickly agrees to the Sales Manager's requests.

A key implication of these findings is that when seeking to increase Sales/Marketing cooperation, senior management must be explicitly seen to support the CFR, though the choice of linkage device used seems relatively unimportant. Also, if greater Sales/Marketing integration is required in more complex organizations senior management may need to make greater efforts and use more linkage devices.

\subsubsection{Managerial Use of Influence Tactics}

In the previous section we reviewed various types of lateral linkage devises that may be useful in building or sustaining effective Sales/Marketing CFRs. It this current section we examine a special form of informal managerial communication - influence tactics. As we have established, Sales and Marketing are highly interdependent, but at the same time, have different issues, priorities, and timeframes. Consequently, Sales 
Managers and Marketing Managers may not always agree on what needs to be done in a given situation, or how it might best be achieved.

In such situations managers therefore need to try and convince other managers that their ideas, plans, or approaches are the best way to proceed. This is where influence tactics fit in. 'Influence tactics' are attempts by one manager ('the agent') to secure compliance or cooperation from another manager (the 'target') (Yukl, 2002). It is well known that a manager's effectiveness is determined partly by their level of informal influence, so it is in the interests of managers to understand the nature of these tactics, and how they might be usefully employed in Sales/Marketing CFRs.

The type of influence tactics that can be used differ widely, though they can be broadly categorised into two groups: hard/coercive tactics, and soft/non-coercive tactics. The hard/coercive tactics involves promises of rewards for compliance, or threats of punishment for non-compliance (e.g., threats or legalistic pleas). The second type, soft/non-coercive tactics, appeal to the target's values, emotions, morality, or altruism, or debts owed to the person making the request (e.g., rational persuasion or consultation). We will begin with a discussion of these tactics first, before we move onto the hard/coercive tactics.

In CFRs between managers on the same level in an organization's hierarchy (such as Sales Managers and Marketing Managers), non-coercive tactics are far more likely to be used than coercive tactics (Yukl and Falbe, 1990). There are a wide range of non-coercive tactics, including rational persuasion (in which a manager uses explanations, logical arguments, and factual evidence to demonstrate that a request is feasible and relevant) and consultation (inviting the other manager to plan how to carry out a request, or implement a change). Collaboration involves the agent offering to provide resources or assistance to the target to carry out the request, and involves a 
joint effort to achieve the objective. Ingratiation is where the agent gives compliments, does unsolicited favours, and acts in a friendly or respectful way. Also, inspirational appeals seek a target's compliance or cooperation by appealing to the target's emotions or needs, values, hopes, and ideals.

The second broad category of tactics is the hard/coercive ones. These include the use of threats where the agent makes it clear that they will take actions which will be adverse to the target if they fail to perform the desired action. Also, there are legalistic pleas where an agent cites either legalistic, contractual, or informal agreements that require or suggest that the target performs a certain action (Frazier and Summers, 1984). These are used less frequently in Sales and Marketing CFRs. Both coercive and non-coercive tactics are all considered to be effective in achieving the compliance or cooperation of another manager. However, the soft/non-coercive tactics should be used first in any attempt to secure another manager's cooperation, rather than resorting immediately to coercive tactics, especially as these managers are interdependent and rely on each other to get their jobs done. It is therefore unwise to begin an influence attempt with a coercive tactic, as they have been found to be negatively correlated with interpersonal trust and also with the perceived effectiveness of the CFRs (Dawes and Massey, 2006).

The Sales Manager's Tale provides an example of the successful use of a noncoercive influence tactic (rational persuasion), when the Sales Manager convinces the Production Manager to schedule the new order into production on the basis that these large ongoing orders will strengthen the Production Manager's case for a capital expenditure request to justify the purchase of two new machines. In summary, Sales Managers should carefully consider the means by which they attempt to influence Marketing Managers. A short-term strategy of getting the job done no matter what the 
cost to the relationship is almost certainly the wrong approach. CFRs are vital to an organization's effective operations, and should not be damaged through the capricious use of coercive tactics. CFRs require nurturing, and it is important for Sales Managers to have a range of soft, socially acceptable influence tactics at their disposal, for use in their CFRs with Marketing Managers. This section has reviewed the importance of influence tactics, which are just one specialized form of communication. In the next section we shall consider other, more general forms of communication.

\subsection{COMMUNICATION BETWEEN SALES AND MARKETING FUNCTIONS}

One of the greatest barriers to effective CFRs is poor communication, hence a discussion about communication types and level is essential to any review of CFRs (e.g., Fisher, Maltz and Jaworski, 1997; Griffin and Hauser, 1996; Rouzies et al., 2005; Yandle and Blythe, 2000). Improvements in communication are associated with a better understanding of each other's perspectives and are important to establishing mutual appreciation of each other's roles. Improvements in interdepartmental communication can also enhance strategy formulation and reduce dysfunctional conflict.

A key issue therefore, is what forms of communication exist between these two managers, and what are their effects? Early approaches to communication in CFRs emphasised the quantity, or frequency of communication between managers. An assumption behind this approach is that greater quantity/frequency of communications, the more effective the CFR. A more realistic approach to understanding communication in Sales/Marketing CFRs is to recognise that “communication” has multiple forms. There are for example formal communications such as memoranda and reports, and informal communication such as impromptu conversations at the coffee machine. As noted earlier section, often the formal side of 
the organization is less important than the informal. As early as 1938 Chester Barnard noted in "The Functions of the Executive";

"You can't understand an organization or how it works from its organizational chart, its charter, rules and regulations.... Learning the organization ropes in most organizations is chiefly learning who's who, what's what, why's why of its informal society.... In fact, informal organization is so [taken for granted].... that we are unaware of it, seeing only a part of the specific interactions involved” (Barnard, 1938:12).

The key point to remember is that whilst formal communications have an important role in coordination and integration, they may be less powerful than informal communications, as these seem more helpful to managers in fostering effective CFRs. As anyone who has worked in an organization knows, a casual chat with a key manager will often reveal more about what is going on than a formal exchange, e.g., a question asked during a formal meeting.

Turning now to the effectiveness of frequent communications between managers as an integrating tool, one should be cautious in assuming that mere frequency is sufficient. What evidence exists on this suggests in fact that high frequency communications between peer managers can actually damage the CFR. Dawes and Massey (2005) found that greater communication frequency between Sales Managers and Marketing Managers was strongly associated with an increase in dysfunctional conflict between those two managers. It is not difficult to see why. If one manager sends multiple e-mails, memos, telephones them many times a day, or leaves multiple voice mails and the like to another manager, the manager receiving those communications would rightly feel under siege, as though they are being closely monitored, or badgered by the sender. There is an inherent danger in simply increasing frequency of communication as it may overload the recipients and may possibly lead to acrimony (Rouzies et al., 2005). Neither do frequent communications 
appear to have a direct effect on the perceived effectiveness of the Sales/Marketing CFR (Dawes and Massey, 2006).

This then begs the question: what forms of communication appear to be best at integrating Sales and Marketing and improving this CFR? It is suggested that "bidirectional communication" (i.e., two-way communication), and “communication quality” may be the two forms of communication that are most effective in CFRs. Communication "quality" is the extent to which the receiver of the communications perceives the content of the communication to be credible, understandable, relevant, and useful for the task at hand (e.g. Souder, 1988; Menon, Bharadwaj and Howell, 1996). It is not difficult to see why these two forms of communication are likely to be effective. Bidirectional communication for example signals a collaborative relationship where each party responds to the other's messages. This allows them to clarify issues, and iron out problems in joint working. Accordingly, bidirectional communication has been found to significantly decrease dysfunctional conflict in Sales/Marketing CFRs, increase functional conflict, and increase the perceived effectiveness of the CFR (Dawes and Massey, 2005; Massey and Dawes, 2006). Similarly, the quality of communication between managers appears to be important, as it has been found to decrease dysfunctional conflict, and increase both functional conflict and the effectiveness of the Sales/Marketing CFR.

This review of inter-departmental communications raises the following points; first, do not place an overemphasis on formal communications. These are useful and important, but it is likely that informal communication has an equal, if not greater influence on building effective Sales/Marketing CFRs. Second, one should not fall into the "mere frequency” fallacy, that what needs to be done to improve CFRs is to communicate more. The reverse in fact seems to be true, i.e., that high frequency 
communication actually works against the building of effective CFRs. Following on from this, when we do communicate, make sure that what we say is important, relevant, credible and useful. The receiver is interested in information that helps them in their job, and not in communication for communication's sake. If we demonstrate our competence and credibility to another manager via high quality communications, that manager may then start to trust in us. Third, managers need to build reciprocal communications with other interdependent managers. An effective Sales/Marketing CFR is more likely to develop when the two managers freely exchange ideas and information and provide feedback to each other on issues of importance. Good communications can also lead to a greater understanding of each other's roles and may eventually lead to trust and respect. The next section will consider the role of trust in the intra-functional relationship as well as in the inter-organizational relationship between suppliers and their customers.

\subsection{THE ROLE OF TRUST}

This section will review what is known about interpersonal trust and its effects in Sales/Marketing CFRs, as well as the role of inter-organizational trust and how this may be influenced by Sales/Marketing CFRs. As Golembiewski and McConkie (1975) noted, there is probably no other single variable so important in influencing interpersonal and group behaviour.

\subsubsection{Types of Interpersonal Trust}

Interpersonal trust is particularly important in CFRs because as we have noted earlier, managers are often highly interdependent, and poor CFRs can therefore have adverse effects on other managers, their departments, and the organization itself. Usually organizations try to reduce the risks of non-performance by peer managers, and to control CFRs by using formal policies and procedures. The problem is that whilst 
these formal bureaucratic measures are legitimate tools for senior managers to use, they tend to be relatively ineffective and weak impersonal substitutes for interpersonal trust to manage CFRs and processes within organizations (Agyris, 1994; Sitkin and Roth, 1993).

Many of an organization's key activities are potentially affected by the presence (or absence) of interpersonal trust. Trust within CFRs can have wide ranging positive outcomes, such as improving organizational decision making (Schwenk, 1990; Williams, 2001), and overall organization performance (Song, Xie and Dyer, 1997), while low trust is associated with reduced cooperation and coordination on strategic issues (Ruekert and Walker, 1987). Trust can also help motivate groups towards joint efforts, and better performance (e.g., Dirks, 1999) and when it is absent, it can adversely affect team performance (e.g., Porter and Lilly, 1996). Trust between departmental managers can also improve cross-functional coordination, and this can in turn, markedly improve service delivery to external customers (e.g., George, 1990; Lovelock, 2000). Interpersonal trust is therefore important in Sales/Marketing CFRs, given the extent to which these two functions must interact on day-to-day issues, and because Sales implement Marketing’s strategies at the operational level (Strahle, Spiro and Acito, 1996).

Various types of trust are identified in the literature, though a well-established body of work suggests that there are two main forms. One is the rational, task-related form of trust, and relates to the extent to which the other person in the CFR is competent and reliable in doing their job. This form of trust is known as cognitionbased trust. Other studies refer to this form of trust as credibility (e.g., Moorman et al., 1992). If this form of trust exists in Sales/Marketing CFRs, the two managers trust each other because there is good evidence, from previous occasions in which they 
have worked together, that the other manager is competent, reliable, and dependable. Consequently, where this form of trust is low or absent, it will be associated with low relationship effectiveness (Massey and Dawes, 2007).

The other form of trust is affect-based trust, and this form is where emotional bonds have formed between managers in the CFR. In this case, a manager is trusted because they exhibit genuine care and concern for the other person in the CFR. Relationships low in affect-based trust will not enjoy the benefits of the voluntary assistance provided by the other manager in that CFR. This form of trust helps the relationship in ways that are over and above the normal work-related assistance and support provided under conditions of cognition-based trust. As such, a CFR in which this form of trust exists can provide extra performance benefits than a CFR in which only cognition-based trust exists, as managers will actively look for opportunities to meet that peer manager's needs (McAllister, 1995). The Sales Manager’s Tale provides a number of examples of how trust can affect CFRs. Cognition-based trust exists between the R\&D Manager and the Sales Manager, because they have worked well together before, and affect-based trust has emerged, because they like each other, and try to help each other achieve personal, and work-related goals.

In summary, whilst there is an important role for formal coordination to improve Sales/Marketing CFRs, this is by no means the only mechanism through which improved CFRs and better coordination is achieved. It is likely that informal factors such as interpersonal trust are equally, if not more powerful than the formal factors. It is therefore useful for senior managers to understand this, and to consider means by which these forms of trust might be fostered. 


\subsubsection{Inter-Organizational Trust}

In an uncertain world and an increasingly complex market environment interpersonal and inter-organization trust are becoming more and more critical to successful businesses relationships and superior performance (Lane, 2002). Interpersonal trust has been considered in the previous section, but it is also important to consider interorganizational trust, as it is a critical coordination mechanism for successful trade (Bradach and Eccles, 1989). Sato (2002) characterizes inter-organizational trust between trading organizations as consisting of contractual based trust, goodwill trust and competence based trust. Goodwill trust may be similar to affect based trust in sentiment and competence based trust may be akin to cognition based trust. The types of trust outlined by Sato (2002) are important in other exchange relations relevant to Sales Managers, but it should be noted that almost all trust will begin with interpersonal trust being established between individuals.

Once communication is established between, for example, the salesperson and the customer, trading agreements may be made and trust established based on the belief that each organization will honour their agreements to their mutual advantage (contractual based trust) (Sato, 2002). Over time, the customer begins to trust in the ability of the organization to deliver what has been agreed and builds an understanding their way of working, which becomes competence based trust. In addition, the customer builds a relationship with customer-facing individuals within the organization and recognises the individual's contribution to transactions (Sato, 2002). As the relationships develop between individuals within both companies, goodwill trust may become established. Goodwill trust is the belief that their business is important to the corresponding organization and that they also wish to invest in the relationship (Sato, 2002). The customer may then invest more with the supplier, 
thereby exposing themselves to greater risk. It is goodwill trust and competence based trust that lack of collaboration between sales and marketing may damage.

As trust develops between organizations there may be an increase in interdependence, and as time goes on there is a tendency to create shared resources and increased social capital (Rousseau et al, 1998). Social capital has been described as the benefits and resources created through networked connections between organizations, groups and individuals (Tsai and Ghoshal, 1998; Koka and Prescott, 2002). Customers and organizations (suppliers) may develop social capital as they exchange resources and search for solutions to satisfy consumers. Social capital may also be developed intra-organizationally, through personal relationships between members of the sales and marketing teams when they collaborate to create solutions to marketing issues.

Trust is a fragile commodity (Lane, 2002) and is built up over an extended period, but it may be permanently damaged by individual incidents or other's actions e.g., promises (e.g., support for sales promotions or customized offers) made by sales staff are not carried through by the organization, or marketing collateral is not understood and conveyed by sales staff. Sales staff aim to build trust with their customers, but customers may stop relying on the organization and may even question its reputation if its trust in the organization as represented by sales and marketing function is compromised. Damaged trust between the organization and customer may result in falling sales as customers replace the organization's offer with those of its competitors.

\subsection{CONCLUSIONS}

The CFR between sales and marketing is complex and vital to creating a successful sales/market orientated organization. This chapter has reviewed the available 
literature and highlighted some of the current thinking about this intra-organizational relationship. It is established early in the chapter that effective CFRs between Sales and Marketing are essential in the creation of improved performance, both in terms of metrics, and psychosocial outcomes, although it is only recently that this interface has attracted attention from academics and practitioners.

The chapter identifies the levels and types of conflict found in Sales/Marketing CFR based on studies in the UK, US, Europe and Australia. The Sales/Marketing interface demonstrates both dysfunctional and functional conflict and managers should be aware of how these types of conflict operate. It was found that functional conflict is required to retain a necessary tension between the two groups, challenge their assumptions and helps to develop creativity. However, the growth of dysfunctional conflict should be avoided and Senior Managers should be aware of strategies and techniques that may be employed to improve the CFR.

A number of factors may be considered to influence the effectiveness of the Sales and Marketing CFR. Structural and bureaucratic factors were considered and it was found that formalization helped to promote CFRs in the Marketing/R\&D interface by reducing confusion, because staff know what they are expected to do and this helps coordinate effort. However, centralization, where decisions are made at higher levels in an organization's hierarchy and disseminated, may reduce the amount of cross-functional communication. Location (placing sales and marketing in one office or being geographically distant) and physical structure (separated or joint departments) on the other hand were found to have little impact on the operation of the Sales/Marketing CFR. Although there is some evidence to indicate that placing a senior manager in charge of both functions may lead to a perception that integration is improved. 
Senior management's attitudes towards improving CFRs emerged as a key factor and managers should take responsibility for the complex relationship between Sales and Marketing, and give staff clear guidance on what is expected from them or they may not prioritize collaboration. This may not be as easy as it first appears because senior managers may experience difficulty in balancing the imperatives of short-term and long-term objectives. To overcome this problem it has been suggested that joint planning with Sales Managers and Marketing Managers may provide an effective basis for aligning objectives. If targets are set jointly then the overall direction and individual contributions to achieving objectives may become explicit, and the understanding of each other's roles should be improved. Senior managers should be able to clarify overlapping activities and remove role ambiguity.

There are a number of tools and techniques that may be used by managers and senior managers to improve the sales and marketing CFR. Studies of other CFRs have outlined a number of lateral linkage devices that may be effectively employed by managers. The conclusion was drawn is that complex organizations require greater efforts to cross-functionally relate and may need to employ a greater number of lateral linkage devises, but that the choice of linkage device used seems relatively unimportant as long as the senior management are seen to explicitly support CFRs. Influence tactics may be used between managers when they do not agree on what needs to be done in a given situation or how it might best be achieved. They will then need to try and convince other managers that their ideas or plans will succeed and gain their 'buy-in'. It is well known that a manager's effectiveness is determined partly by their level of informal influence, so it is in the interest of managers to understand the nature of these tactics, and how they might be usefully employed in Sales/Marketing CFRs. Two types of tactics were reviewed hard/coercive tactics (e.g., 
threats or legalistic pleas) and soft/non-coercive tactics (e.g., rational persuasion or consultation). Both are considered to be effective in achieving the cooperation of another manager, but it is recommended that soft/non-coercive tactics should be used in the sales and marketing CFR before resorting to coercive tactics, especially as these managers are interdependent and rely on each other to get their jobs done. CFRs require nurturing, and it is important for Sales Managers to have a range of soft, socially acceptable influence tactics at their disposal, for use in their CFRs with Marketing Managers.

Existing literature highlights that effective communications are essential to the operation of any CFR, but that there is an inherent danger in simply increasing frequency of communication, as it may overload the recipients and may possibly lead to acrimony. Further, communications should be important, relevant, credible and useful to the recipients. Communication should be bidirectional, thereby building reciprocal communications with other interdependent managers. An effective Sales/Marketing CFR is more likely to develop when the two managers freely exchange ideas and information and provide feedback to each other on issues of importance. There are for example formal communications such as memoranda and reports, and informal communication such as impromptu conversations at the coffee machine. Often the formal communication side is less important than the informal, as these are likely to build into personal relationships and trust.

Trust is the last element of the Sales/Marketing CFR to be reviewed in the chapter. Trust is critical to successful CFRs and can have wide ranging positive outcomes, such as improving organizational decision making and information flows. When trust is absent, it can adversely affect team and business performance. Cognition-based trust (that the other party is competent and reliable) between 
departmental managers can improve cross-functional coordination, and this can in turn, markedly improve service delivery to external customers. The other form of trust is affect-based trust, where emotional bonds have formed between managers in the CFR. This form of trust can also provide extra performance benefits as managers will actively look for opportunities to meet the corresponding manager's needs. Improvements in inter-personal trust positively affect CFRs, but they also affect the organizational trust between suppliers and buyers. The development of contractual based trust, goodwill trust and competence based trust may be supported or destroyed by effective CFRs, and demonstrates why CFRs are so important to improving customer satisfaction and business performance, as CFRs are based on trust. In response to the increasing complexity of the sales environment and the growing demands of customers Sales Managers and Marketing Managers should aim to find a common understanding, and to improve their CFR as a basis of developing solutions for customers. Improving collaboration between Sales and Marketing may be assisted by senior managers developing strategies to help manage any dysfunctional conflict in the Sales/Marketing CFR, employ lateral linkage devices to facilitate integration, and engage in joint decision-making processes, so that Sales Managers and Marketing Managers are aware of each others perspectives and can establish clear lines of communication. Sales Managers and Marketing Managers should be aware of their role in achieving organizational and departmental objectives and aim to establish good communication practices and trust in their relationship. Improved collaboration between Sales and Marketing through more effective CFRs can lead to superior profit levels and greater customer satisfaction. 


\section{References}

Agyris, Chris A. (1994), “Litigation Mentality and Organizational Learning.” In The Legalistic Organization. Eds. S.B. Sitkin and R.J. Bies. Sage, Thousand Oaks, CA.

Aiken, M. and Hage, J. (1968), “Organizational Interdependence and Intraorganizational Structure”, American Sociological Review, 33, 912-930.

Allen, Thomas J., and A.R. Fustfeld (1975), "Research Laboratory Architecture and the Structuring of Communications,” R\&D Management, 5 (2), 153-164.

Amason, A.C. (1996), "Distinguishing the Effects of Functional and Dysfunctional Conflict on Strategic Decision Making: Resolving a Paradox for Top Management Teams,” Academy of Management Journal, 39 (2), 123-148.

Anderson, J.C. and Narus, J.A. (1990), “A Model of Distributor Firm and Manufacturer Firm Working Partnerships,” Journal of Marketing, 54 (January), 42-58.

Anderson, R, E. Dubinsky, A. J. and Mehta, R (1999). “Sales Managers: Marketing's Best Example of the Peter Principle”, Business Horizons, Vol. 42 (1), pp 19-26.

Arthur, L. B. (2002), “Guided Selling: Merging Marketing \& Sales” available at: http://www.okc.marketingpower.com/contenet-printer-Friendly.php?\&Item_ID =15696 (accessed 28 July 2005).

Athens, D. (2002) 'Integration Between Marketing and Sales'. Available at: http://www.marketingpower.com/live/contenet-printer-friendly.php?\&Item_ID =16836 [accessed 19 March 2002].

Ayers, D., Dahlstrom, R. and Skinner, S.J. (1997), “An Exploratory Investigation of Organizational Antecedents to New Product Success”, Journal of Marketing Research, 34 (February), 107-116.

Ballantyne, David (1997), “Internal Networks for Internal Marketing,” Journal of Marketing Management, 13, 343-366.

Barclay, Donald W. (1991), "Interdepartmental Conflict in Organizational Buying: The Impact of Organizational Context,” Journal of Marketing Research, 22 (May), 145-159.

Baron, R. (1991), “Positive Effects of Conflict: A Cognitive Perspective,” Employee Response and Rights Journal, 4(1), 25-36.

Barnard, Chester (1938), The Functions of the Executive, Cambridge, MA: Harvard University Press.

Bartlett C.A. and Ghoshal S., (2000) "Matrix Management: Not a Structure, a Frame of Mind”. Harvard Business Review, Vol. 68, No. July/ August, pp. 138-145. 
Beverland, M., Steel, M. and Dapiran, G.P. (2006), "Cultural frames that drive sales and marketing apart: An exploratory study", Journal of Business and Industrial Marketing, Vol. 21 No. 6, pp. 386-94.

Biemans, W.G. and Brenčič, M.M. (2007), "Designing the marketing-sales interface in b2b firms”, European Journal of Marketing, Vol. 41 No. 3/4, pp. 257-273.

Bradach, J. L and Eccles, R.G. (1989) "Price, Authority and Trust: From Ideal Types to Plural Forms” Annual Review of Sociology, 15, 97-118.

Burns, T. and Stalker, G.M. (1961), The Management of Innovation, Tavistock, London.

Butler, Sarah Lorge and Erin Strout (2003), “Happy Together,” Sales \& Marketing Management, 155 (4), 51.

Carpenter, Philip (1992), “Bridging the Gap Between Marketing and Sales,” Sales \& Marketing Management, (March), 29-31.

Cass, E.L. and F. G. Zimmer eds., (1975), Man and Work in Society, "The Hawthorne Studies: A Synopsis,” New York: Nostrand Reinhold, pp. 278-306.

Cespedes, Frank V. (1993), "Coordinating Sales and Marketing in Consumer Goods Firms,” Journal of Consumer Marketing, 10 (2), 37-55.

Cespedes, Frank.V. (1994), “Industrial Marketing: Managing New Requirements,” Sloan Management Review, Spring, 45-60.

Colletti, J. A., and Chonko, L. B. (1997) 'Change Management Initiatives: Moving Sales Organizations to High Performance’. Journal of Personal Selling and Sales Management 17 (Spring): 1-30.

Cosier, R. A. (1978), "The Effects of Three Potential Aids for Making Strategic Decisions on Predictions Accuracy," Organizational Behavior and Human Performance, (22), 295-306.

Dawes, Philip L. and Graham R. Massey (2005), “Antecedents of Conflict in Marketing's Cross-functional Relationship with Sales,” European Journal of Marketing, 39 (11/12), 1327-1344.

Dawes, P.L. and Massey, G.R. (2006), “A Study of Relationship Effectiveness between Marketing and Sales Managers in Business Markets”, Journal of Business and Industrial Marketing, 21 (6), 346-360.

De Dreu, C.K.W. (1997), "Productive conflict: The importance of conflict management and conflict issues,” De Dreu, C.K.W. and Van De Vliert, E. (Eds.), Using Conflict in Organisations, 1997, Sage, London, pp. 9-22. 
De Dreu, C.K.W. and L.R. Weingart (2003), “Task Versus Relationship Conflict, Team Performance, and Team Member Satisfaction: A Meta Analysis,” Journal of Applied Psychology, 88 (4), 741-749.

Dewsnap, B. and Jobber, D. (2000), “The sales-marketing interface in consumer packaged-goods companies: A conceptual framework”, Journal of Personal Selling and Sales Management, Vol. 20 (Spring), pp. 109-119.

Dewsnap, B. and Jobber, D. (2002), “A social psychological model of relations between marketing and sales”, European Journal of Marketing, 36 (7/8), 874-894.

Dirks, Kurt T. (1999), “The Effects of Interpersonal Trust on Work Group Performance,” Journal of Applied Psychology, 84, (3), 445-455.

Filley, A. (1970), “Committee Management: Guidelines from Social Science Research.” California Management Review, 13 (Fall), 13-21.

Fisher, Robert J., Elliot Maltz, and Bernard J. Jaworski (1997), “Enhancing Communication Between Marketing and Engineering: The Moderating Role of Relative Functional Identification,” Journal of Marketing, 61, (July), 54-70.

Frazier, G.L. and Summers, J.O. (1984), "Interfirm Influence Strategies and their Application within Distribution Channels”, Journal of Marketing, 48 (Summer), 4355.

George, William R. (1990), "Internal Marketing and Organizational Behavior: A Partnership in Developing Customer-Conscious Employees at Every Level,” Journal of Business Research, 20, 63-70.

Germain, R., Droge, C., and Daugherty, P. J. (1994) 'The Effects of Just-in-Time Selling on Organisational Structure: An Empirical Investigation’. Journal of Marketing Research 31 (November): 471-83.

Golembiewski, R.T. and M. McConkie (1975), “The Centrality of Interpersonal Trust in Group Processes.” In Theories of Group Process. Ed. C. L. Cooper. John Wiley and Sons, New York.

Griffin, Abbie and John R. Hauser (1996), “Integrating R\&D and Marketing: A Review and Analysis of the Literature,” Journal of Product Innovation Management, 13, 191215.

Grönroos, Christian (1981), "Internal Marketing - An Integral Part of Marketing Theory,” in: Marketing of Services, Donnelly, J.H., and W.R. George, American Marketing Association, Chicago IL: 236-238.

Guenzi, P. and Troilo, G. (2006), “Developing marketing capabilities for customer value creation through marketing-sales integration”, Industrial Marketing Management, 35 (8), 974-88. 
Guenzi, Paolo and Gabriele Troilo (2007), "The Joint Contribution of Marketing and Sales to the Creation of Superior Customer Value.” Journal of Business Research 60, 98-107.

Gummesson, Evert (1991), "Marketing Orientation Revisited: The Crucial Role of the Part-Time Marketer,” European Journal of Marketing, 25 (2), 60-75.

Gupta, Ashok K., S. P. Raj, and David Wilemon, (1986), “A Model for Studying the R\&D-Marketing Interface in the Product Innovation Process,” Journal of Marketing, 50, (April), 7-17.

Hammer, M. (2001) Hammer "The Agenda: What every Business Must Do To Dominate the Decade". Three Rivers Press. New York:

Holden, J. (1999) World Class Selling. New York: John Wiley and Sons.

Homburg, C. and Jensen, O. (2007), "The thought worlds of marketing and sales: Which differences make a difference?” Journal of Marketing, 71 (July), 124-42.

Homburg, C., Workman, J.P. Jr. and Krohmer, H. (1999), “Marketing’s influence within the firm”, Journal of Marketing, 63 (April), 1-17.

Jaworski, Bernard J. and Ajay K. Kohli (1993), “Market Orientation: Antecedents and Consequences,” Journal of Marketing, 57 (2), 53-70.

Jehn, K.A. and Mannix, E. A. (2001). 'The Dynamic Nature of Conflict: A Longitudinal Study of Intragroup Conflict and Group Performance', Academy of Management Journal, 44 (2), 238-251.

Kohli, Ajay K., and Bernard J. Jaworski (1990), "Market Orientation: The Construct, Research Propositions, and Managerial Implications,” Journal of Marketing, 54 (April), 1-18.

Koka, R.B. and Prescott, J. (2002)“Strategic alliances as social capital: a multidimensional view” Strategic Management Journal 23, 795-816

Kotler, Philip, Neil Rackham, and Suj Krishnaswamy (2006), "Ending the War between Sales and Marketing," Harvard Business Review, July-August, 68-78.

Krohmer, H., Homburg, C., and Workman, J. P. (2002) 'Should marketing be crossfunctional? Conceptual development and international empirical evidence’. Journal of Business Research 55: 451-65.

Lane, C. (2002) "Introduction: Thoeries and Issues in the Study of Trust”. In. Trust Within and Between Organizations. (Ed) Lane, Christel and Bachmann, Reinhard, Oxford: Oxford University Press. pp.1-30

Lawrence, Paul R. and Jay W. Lorsch (1967a), Organization and Environment, Homewood IL: Irwin-Dorsey. 
Lawrence, Paul R. and Jay W. Lorsch (1967b), “New Management Job: The Integrator,” Harvard Business Review, November-December, 142-151.

Le Meunier-FitzHugh, K. and Piercy, N. F. (2007a). Exploring collaboration between sales and marketing. European Journal of Marketing, 41 (7/8), 939-955.

Le Meunier- FitzHugh, K. and Piercy, N. F. (2007b) "Does Collaboration Between Sales and Marketing Affect Business Performance?” Journal of Personal Selling and Sales Management 27 (3), 207 - 220.

Le Meunier- FitzHugh, K. and Piercy, N. F. (2008) "The importance of organisational structure for collaboration between sales and marketing” Journal of Management Studies. 34(1) 19-36

Le Meunier- FitzHugh, K. and Piercy, N. F. (2009) "Drivers of Sales and Marketing Collaboration in Business-to-Business Selling Organisations” ” Journal of Marketing Management. TBC

Lim, Jeen-Su and David A. Reid (1992), "Vital Cross-Functional Linkages with Marketing,” Industrial Marketing Management, 21, 159-165.

Lorge, S. (1999), "Marketers are from Mars, salespeople are from Venus,” Sales and Marketing Management, 151 (4), 27-33.

Lovelock, Christopher (2000), "Functional Integration in Services,” In Handbook of Services Marketing and Management, Eds. T.A. Schwartz and D. Iaccobucci, Sage Publications, Thousand Oaks, CA: 421-437.

Lucas, George H., and Alan J. Bush (1988), “The Marketing-R\&D Interface: Do Personality Factors Have and Impact?” Journal of Product Innovation Management, 5, 257-268.

Massey, Graham, and Philip L. Dawes (2001), "Integrating Marketing and Sales: The Frequency and Effectiveness of Methods Used in Australia and the United Kingdom," ANZMAC 2001 Conference, Massey University, Auckland, New Zealand, 2001.

Massey, Graham R. and Philip L. Dawes (2006), “A Study of Relationship Effectiveness between Marketing and Sales Managers in Business Markets," Journal of Business and Industrial Marketing, 21 (6), 346-360.

Massey, Graham R. and Philip L. Dawes (2007a), "Personal Characteristics, Trust, Conflict, and Effectiveness in Marketing/Sales Working Relationships.” European Journal of Marketing, 41 (9/10), 1117-1145.

Massey, Graham R. and Philip L. Dawes (2007b), “The Antecedents and Consequence of Functional and Dysfunctional Conflict between Marketing Managers and Sales Managers,” Industrial Marketing Management, 36, 1118-1129. 
Massey, Graham R. and Elias Kyriazis (2007), "Interpersonal Trust between Marketing and R\&D during New Product Development Projects,” European Journal of Marketing, 41 (9/10), 1146-1172.

Matthyssens, P. and Johnston, W. J. (2006) "Marketing and sales: optimization of a neglected relationship”. Journal of Business and Industrial Marketing, 21(6) 338-345.

McAllister, Daniel J. (1995), “Affect- and Cognition-based Trust as Foundations for Interpersonal Cooperation in Organizations," Academy of Management Journal 38 (1), 24-59.

McCann, J. and Galbraith, J.R. (1981), “Interdepartmental Relations”, in Nystrom, P.C. and Starbuck, W.H. (Eds), Handbook of Organizational Design, Volume 2. Remodelling Organizations and their Environment, Oxford University Press, pp. 6084

Menon, Anil, Sundar G. Bharadwaj, and Roy Howell (1996), "The Quality and Effectiveness of Marketing Strategy: Effects of Functional and Dysfunctional Conflict in Intraorganizational Relationships,” Journal of the Academy of Marketing Science, 24 (4), 299-313.

Mintzberg, H. (1979), The Structuring of Organizations, Prentice-Hall, Englewood Cliffs, NJ.

Moorman, Christine, Gerald Zaltman, and Rohit Deshpandé (1992), "Relationships between Providers and Users of Market Research: The Dynamics of Trust within and between Organizations.” Journal of Marketing Research 29 (August): 314-328.

Murray, J. A., O`Driscoll, A. and Torres, A. (2002) "Discovering diversity in marketing practice”, European Journal of Marketing 36 (3), 373-90

Narver, John C. and Stanley F. Slater (1990) “The Effect of a Market Orientation on Business Profitability”, Journal of Marketing, 54 (October), 20-35.

Oliva, R. A. (2006) 'Three key Linkage: improving the connections between marketing and sales, Journal of Business and Industrial Marketing, 21 (6), 395-398.

Olson, E.M., Walker, O.C. Jnr. and Ruekert, R.W. (1995), “Organizing for Effective New Product Development: The Moderating Role of Product Innovativeness,” Journal of Marketing, 59 (January), 48-62.

Olson. E. M., Cravens, D. W., and Slater, S. F. (2001) 'Competitiveness and Sales Management: A Marriage of Strategies’. Business Horizons 44 (March-April): 25-30

Pondy, Louis R. (1967), “Organizational Conflict: Concepts and Models,” Administrative Science Quarterly, 12, 296-320.

Piercy, N. F. (1986), "The role and function of the Chief Marketing Executive and the Marketing Department: A study of Medium-Sized Companies in the UK”, Journal of Marketing Management, 1 (3) 265-298. 
Piercy, N. F. (2006), “The Strategic Sales Organization”, The Marketing Review, 6 (1), 3-28.

Porter, Michael E. (1985), Competitive Advantage, New York: The Free Press.

Porter, T.W. and B.S. Lilly (1996), "The Effects of Conflict, Trust, and Task Commitment on Project Team Performance.” International Journal of Conflict Management 7 (4): 361-376.

Pugh, D., Hickson, D., Hinings, C.R. and Turner, C. (1968), "Dimensions of Organizational Structure,” Administrative Science Quarterly, 13 (June), 65-105.

Rousseau, D. M., Sitkin, S.B., Burt, R. S. and Camerer, C. (1998) "Not so different after all: A cross-Discipline view of Trust” Academy of Management Review. 23 (3), 383-404.

Rouzies, D. Anderson, E. Kohli, A. K. Michaels, R. E. Weitz, B. A. and Zoltners, A. A. (2005). "Sales and Marketing Integration: A Proposed Framework" Journal of Personal Selling and Sales Management. 15 (2), 113-122.

Ruekert, Robert W. and Orville C. Walker (1987a), "Marketing's Interaction with Other Functional Units: A Conceptual Framework and Empirical Evidence,” Journal of Marketing, 51 (January), 1-19.

Ruekert, R. W. and Orville C. Walker (1987b), "Interactions between Marketing and R\&D Departments in Implementing Different Business Strategies,” Strategic Management Journal, 8 (May-June), 233-248.

Sato, M. (2002) “Does Trust Improve Business Performance”, In. Trust Within and Between Organizations. (Ed) Lane, Christel and Bachmann, Reinhard, Oxford: Oxford University Press. pp.88-117

Saghafi, Massoud M., Ashok K. Gupta, and Jagdish N. Sheth (1990), "Marketing/R\&D Interfaces in the Telecommunications Industry,” Industrial Marketing Management, 19, 87-94.

Schmonsees, R. J. (2006), Escaping the Black Hole: Minimizing the Damage from Marketing -Sales Disconnect, Thomson South-Western, Mason.

Schwenk, Charles R. (1989), “A Meta-analysis on the Comparative Effectiveness of Devil’s Advocacy and Dialectical Enquiry,” Strategic Management Journal, 10 (May-June), 303-306.

Schwenk, Charles R. (1990) "Conflict in Organizational Decision Making: An Exploratory Study,” Management Science 36 (4): 436-448.

Sclater. I. (2005), “Sales 4 Marketing?”, The Marketer, 14 (June), 9-21. 
Shapiro, B. (2002), "Want a Happy Customer? Coordinate Sales and Marketing'. Boston: Harvard Business School available at:

[http://hbswk.hbs.edu/pubitem.jhtml?id=3154\&sid=0\&pid $=0 \& \mathrm{t}=$ customer] (accessed April 6, 2006)

Sitkin, S.B. and Roth, N.L. (1993), "Explaining the limited effectiveness of legalistic remedies for trust/distrust”, Organisation Science, 4, 367-92.

Smith, Brock J. and Donald. W. Barclay (1997), “The Effects of Organizational Differences and Trust on the Effectiveness of Selling Partner Relationships,” Journal of Marketing, 61 (January), 3-21.

Smith, Brock J. and Donald. W. Barclay (1999), "Selling partner relationships: The role of interdependence and relative influence”, Journal of Personal Selling and Sales Management, 19 (Fall), 21-40.

Song, M. X., Xie, J. and Dyer, B. (2000) 'Antecedent and Consequences of ConflictHandling Behaviours’ Journal of Marketing, 64, 50-66.

Souder, William E. (1977), "An Exploratory Study of the Coordinating Mechanisms Between R\&D and Marketing as an Influence on the Innovation Process," National Science Foundation, Final Report \# 75-17195, Washington D.C., August 26.

Souder, William E. (1981), “Disharmony between R\&D and Marketing,” Industrial Marketing Management, 10, 67-73.

Souder, William E. (1988), "Managing Relations Between R\&D and Marketing in the New Product Development Process,” Journal of Product Innovation Management, 5 (March), 6-19.

Souder, William E. and Alok K. Chakrabati (1978), “The R\&D/Marketing Interface: Results from an Empirical Study of Innovation Projects,” IEEE Transactions on Engineering Management, EM-25 (4), 88-93.

Strahle, William M., Rosann L. Spiro, and Frank Acito (1996), "Marketing and Sales: Strategic Alignment and Functional Implementation," Journal of Personal Selling and Sales Management, 16 (Winter), 1-20.

Thomas, K. (1990), “Conflict and Negotiation Processes in Organizations,” in M. D. Dunnette (Ed.), Handbook of Industrial and Organizational Psychology. Palo Alto, CA: Consulting Psychological Press.

Thompson, J.D. (1967), Organizations in Action, McGraw-Hill, New York.

Tjosvold, Dean (1985), “Implications of Controversy Research in Management," Journal of Management, 11 (Fall-Winter), 21-37.

Tsai, W. and Ghoshal, S. (1998) "Social capital and value creation: the role of interfirm networks” Academy of Management Journal. 41,.464-477. 
Van de Ven, Andrew (1976), "On the Nature, Formation, and Maintenance of Relations among Organizations,” Academy of Management Review, 4 (October), 24-36.

Vargo, Stephen L. and Robert F. Lusch (2004), “Evolving to a New Dominant Logic for Marketing,” Journal of Marketing, 68 (January), 1-17.

Viswanathan, M., and Olson, E. M. (1992) 'The Implementation of Business Strategies: Implications for the Sales Function'. Journal of Personal Selling and Sales Management 21 (1): 45-57.

Watkins, H. (2003) 'Getting sales and marketing on the same team' available at: http://www,btobonline.com/cgi-bin/article.pl?id=10844 [accessed 22 April 2004].

Weber, M. (1924), The Theory of Social and Economic Organization, (Trans.) Henderson, A.H. and Parsons, T. (1947), The Free Press, New York. (First published in German in 1924).

Webster, F.E. Jnr. (1997), “The future role of marketing in the organisation” Lehmann, D.R. and Jocz, K.E. (Eds.), Reflections on the Futures of Marketing, Marketing Science Institute Cambridge, MA.

Williams, Michelle (2001), "In Whom We Trust: Group Membership as an Affective Context for Trust Development.” Academy of Management Review 26 (3): 377-396.

Williams K.Y. and O-Reilly, C. A. (1998) 'Demography and Diversity in Organization: A 40 years of research', Research in Organizational Behaviour, 20, 77140.

Winer, R. S. (2001), “A Framework for Customer Relationship Management.” California Management Review 43 (4): 89-105.

Workman, J. P., Jr, Homburg, C., and Gruner, K. (1998),’Marketing Organization: An Integrative Framework of Dimensions and Determinants”, Journal of Marketing, 62 (July), 21-41.

Yandle, J. and Blythe, J. (2000) 'Intra-Departmental Conflict between Sales and Marketing: An Exploratory Study’. The Journal of Selling and Major Account Management 2 (3): 13-31.

Yukl, G. (2002), Leadership in Organisations, Prentice Hall, Upper Saddle River, NJ.

Yukl, G. and Falbe, C.M. (1990), "Influence tactics and objectives in upward, downward, and lateral influence attempts”, Journal of Applied Psychology, 75 (2), 132-140.

Zillman, D. (1988), “Cognition-Excitation Interdependencies and Aggressive Behavior,” Aggressive Behavior, 14, 51-64. 